Research Article

\title{
Assessment of genetic mutation frequency induced by oxidative stress in Trypanosoma cruzi
}

\author{
Carolina Furtado Torres-Silva ${ }^{1 *}$, Bruno Marçal Repolês ${ }^{1 *}$, Hugo Oliveira Ornelas ${ }^{1}$, Andréa Mara Macedo ${ }^{1}$, \\ Glória Regina Franco ${ }^{1}$, Sérgio Danilo Junho Pena ${ }^{1}$, Erich Birelli Tahara ${ }^{1}$ and Carlos Renato Machado ${ }^{1}$ \\ ${ }^{1}$ Departamento de Bioquímica e Imunologia, Universidade Federal de Minas Gerais, Belo Horizonte, MG, \\ Brazil.
}

\begin{abstract}
Trypanosoma cruzi is the etiological agent of Chagas disease, a public health challenge due to its morbidity and mortality rates, which affects around 6-7 million people worldwide. Symptoms, response to chemotherapy, and the course of Chagas disease are greatly influenced by T. cruzis intra-specific variability. Thus, DNA mutations in this parasite possibly play a key role in the wide range of clinical manifestations and in drug sensitivity. Indeed, the environmental conditions of oxidative stress faced by $T$. cruzi during its life cycle can generate genetic mutations. However, the lack of an established experimental design to assess mutation rates in $T$. cruzi precludes the study of conditions and mechanisms that potentially produce genomic variability in this parasite. We developed an assay that employs a reporter gene that, once mutated in specific positions, convert G418-sensitive into G418-insenstitive $T$. cruzi. We were able to determine the frequency of DNA mutations in T. cruzi exposed and non-exposed to oxidative insults assessing the number of colony-forming units in solid selective media after plating a defined number of cells. We verified that T. cruzi's spontaneous mutation frequency was comparable to those found in other eukaryotes, and that exposure to hydrogen peroxide promoted a two-fold increase in T. cruzis mutation frequency. We hypothesize that genetic mutations in T. cruzi can arise from oxidative insults faced by this parasite during its life cycle.
\end{abstract}

Keywords: T. cruzi, DNA, mutation frequency, $\mathrm{H}_{2} \mathrm{O}_{2}$.

Received: September 05, 2017; Accepted: November 29, 2017.

\section{Introduction}

Trypanosoma cruzi is the etiological agent of Chagas disease, a complex zoonosis that affects more than seventy genera of mammalian hosts (Zingales et al., 2012; Baptista et al., 2014). According to the World Health Organization (WHO), around 6-7 million people are affected by this disease in 21 countries, most of them in Latin America [WHO Chagas disease (American trypanosomiasis) fact sheet, 2017]. Also noteworthy is the fact that nowadays this disease is spreading to non-endemic regions due to human migration (Schmunis, 2007).

The life cycle of T. cruzi is complex and involves two hosts: an invertebrate and a mammalian. Humans are considered accidental hosts, in which the classic vectorial infection generally occurs at night when the blood-sucking triatomines defecate during feeding (Frasch, 2000). Once the feces droplets expelled by the triatomine reach the bloodstream or get in contact with eyes, nose or mouth mu-

Send correspondence to Carlos Renato Machado. Departamento de Bioquímica e Imunologia, Universidade Federal de Minas Gerais, Belo Horizonte, MG, Brazil. E-mail: crmachad1967@gmail.com

${ }^{\star}$ These authors contributed equally to this work cosa, the infection is then perpetrated (Prata, 2001). Humans may also be infected with $T$. cruzi through blood transfusion, organ transplantation, from mother to infant during pregnancy, laboratory accidents, as well as through ingestion of food contaminated with triatomine feces (Shikanai-Yasuda et al., 1991; de Noya and González, 2015).

Following the infection by $T$. cruzi, a short acute phase characterized by high parasitemia takes place, along with unspecific symptoms (Macedo et al., 2004). During its chronic phase, Chagas disease presents a large spectrum of symptoms and low parasitemia. Interestingly, $30 \%$ of infected humans will develop cardiomyopathy, digestive implications or both (Rassi Jr and Marin-Neto, 2010), and a small percentage of them may still develop neurological symptoms (Prata, 2001). Although the mechanisms and factors influencing this clinical unpredictability have not been fully elucidated, the variability in the course of Chagas disease seems to be related to a number of factors such as parasite strain, host age, reinfection, and genetic factors of both host and parasite (Prata, 2001).

Since 2009, T. cruzi strains have been divided into six discrete taxonomic units, namely $T$. cruzi I - VI, based on its intra-specific genetic variability (Zingales et al., 2009; Baptista et al., 2014). Unquestionably, diverse tissue 
tropisms, response against immune system, and responsiveness to chemotherapy have been frequently observed in Chagas disease (Revollo et al., 1998; Andrade et al., 2010). In fact, genetic factors are able to strictly regulate infection capacity of parasites, as there is a correlation between genetic diversity and rate of success in escaping the host immune response (Frasch, 2000; Burgos et al., 2013).

It has long been known that several microorganisms display intrinsic, spontaneous mutability events that lead to intra-specific genetic diversity (Steinberg et al., 1971; Taddei et al., 1997; Rosche and Foster, 2000). The generation of spontaneous mutation is a very complex subject since several intrinsic and extrinsic factors might be involved in the process - like the environment in which the organism is found (Matic et al., 1997), location of mutation-prone sites in the genome (Patrushev and Minkevich, 2008), and the behavior of the DNA repair system (Hoeijmakers, 2001). However, a number of studies have already shed light on the mechanisms and importance of spontaneous mutation rate in bacteria (Choi et al., 2011; Ford et al., 2013), yeast (Magni and von Borstel, 1962; Glassner et al., 1998; Bensasson, 2011), and in other non-disease causing eukaryotes (Provan et al., 1999; Shikazono et al., 2003). Also, it has already been shown that certain $T$. cruzi haplogroups display mutations in microssatelite alleles after being cultured in media supplemented with hydrogen peroxide $\left(\mathrm{H}_{2} \mathrm{O}_{2}\right)$ (Augusto-Pinto et al., 2003).

Therefore, the study of the mechanisms related to the generation of genetic mutations and diversity in $T$. cruzi is imperative since they may play a role in how this parasite deals with genotoxic stress and drug response; in fact, experimental analysis of the antigenic diversity generation remains a challenge since few works tried to investigate $T$. cruzi's mutation rate. In this work, we developed a model that allows the detection of mutational events through the selection of $T$. cruzi resistant to the aminoglycoside G418. We found that the mutation frequency in this parasite is similar to other eukaryotic cells, being substantially increased by challenging $T$. cruzi with exogenous $\mathrm{H}_{2} \mathrm{O}_{2}$. Since $T$. cruzi has to cope with oxidative stress situations during its complex life cycle (Piacenza et al., 2009; Machado-Silva et al., 2016), we hypothesize that immunologic evasion and chemotherapy resistance in Chagas disease could be associated to the generation of genetic variability in $T$. cruzi enhanced by oxidative stress conditions.

\section{Material and Methods}

\section{Plasmid construction and bacterial transformation}

Wild-type Neo $\left(\mathrm{Neo}^{\mathrm{WT}}\right)$ and its mutant variants $\mathrm{Neo}^{\Delta 90}, \mathrm{Neo}^{\Delta 180}, \mathrm{Neo}^{\Delta 270}, \mathrm{Neo}^{\text {stop }}$, and $\mathrm{Neo}^{\text {stopT }} \rightarrow \mathrm{G}-$ were amplified by PCR from the pROCK_Neo vector (da Rocha et al., 2004), using the primers indicated in Table 1. All resultant amplicons (Table 1) were digested with XhoI and $X b a \mathrm{I}$ and then ligated to pMAL-c2G (New England Biolabs
Table 1 - Primers used for reporter construction.

\begin{tabular}{|c|c|c|}
\hline Primer \# & Name & Sequence \\
\hline 1 & $\mathrm{Neo}^{\mathrm{WT}}$ FW & ATGGGATCGGCCATTGAACA \\
\hline 2 & $\mathrm{Neo}^{\Delta 90}{ }_{-} \mathrm{FW}$ & ATGACAATCGGCTGCTCTGATGC \\
\hline 3 & $\mathrm{Neo}^{\Delta 180} \mathrm{FW}$ & ATGAATGAACTGCAGGACGAGGC \\
\hline 4 & $\mathrm{Neo}^{\Delta 270} \mathrm{FW}$ & ATGGGAAGGGACTGGCTGCTATT \\
\hline 5 & $\mathrm{Neo}^{\text {stop }} \mathrm{FW}$ & ATGTGATCGGCCATTGAA \\
\hline 6 & $\mathrm{Neo}^{\text {stopT }} \rightarrow$ G_FW & ATGGAACAAGATGGATTGCA \\
\hline 7 & $\mathrm{Neo}^{\text {all }} \mathrm{RV}_{\mathrm{R}}$ & TCAGAAGAACTCGTCAAG \\
\hline 8 & $\mathrm{Neo}^{\mathrm{Seq}} \mathrm{RV}$ & ACAGGTCGGTCTTGACA \\
\hline
\end{tabular}

Inc., Massachusetts, USA) previously digested with the same endonucleases. Electrocompetent Escherichia coli DH5 $\alpha$ (Gonzales et al., 2013) were transformed with ligation products and plated onto 2xYT medium $[1.6 \%$ tryptone, $1.0 \%$ yeast extract, $0.5 \% \mathrm{NaCl}(\mathrm{pH} 7.0)$ ] supplemented with $100 \mu \mathrm{g} / \mathrm{mL}$ ampicillin. Bacterial positive clones were screened using the colony PCR method (Bergkessel and Guthrie, 2013) and further isolated.

\section{Bacterial kanamycin resistance assay}

DH5 $\alpha$ positive clones for all Neo constructs (Table 1) were grown in $2 \mathrm{xYT}$ liquid medium supplemented with $100 \mu \mathrm{g} / \mathrm{mL}$ ampicillin, under orbital agitation (180 rpm) at $37^{\circ} \mathrm{C}$ for $16 \mathrm{~h}$. Bacterial cells were then subject of a serial dilution (suspensions with final concentrations of $10^{-4}, 10^{-6}$, $10^{-8}$, and $10^{-10}$ cells $/ \mathrm{mL}$ ), and $2.5 \mu \mathrm{L}$ of each suspension were added onto plates containing $2 x Y T$ solid medium (liquid 2xYT plus $2.0 \%$ agar) supplemented with $100 \mu \mathrm{g} / \mathrm{mL}$ ampicillin and $0.1 \mathrm{mM}$ isopropyl $\beta$-D-1-thiogalactopyranoside (IPTG) in the presence or absence of either 10 $\mu \mathrm{g} / \mathrm{mL}$ kanamycin or $10 \mu \mathrm{g} / \mathrm{mL}$ neomycin. Plates were incubated at $37{ }^{\circ} \mathrm{C}$ for $18 \mathrm{~h}$ at the end of which they were photo-documented.

\section{T. cruzi transfection, selection, and genotyping of transfected clones}

Epimastigotes of T. cruzi clone CL Brener were grown in liver infusion tryptose medium $[0.9 \%$ liver infusion broth, $0.5 \%$ tryptose, $0.1 \% \mathrm{NaCl}, 0.8 \% \mathrm{Na}_{2} \mathrm{HPO}_{4}$, $0.04 \% \mathrm{KCl}, 0.2 \%$ hemin, $10 \%$ fetal bovine serum; 200 $\mu \mathrm{g} / \mathrm{mL}$ streptomycin; $200 \mu \mathrm{g} / \mathrm{mL}$ penicillin (LIT); $\mathrm{pH} 7.2$ ], at $28{ }^{\circ} \mathrm{C}$. Cells were transfected by electroporation, as described elsewhere (da Rocha et al., 2004), using the pROCK_Hygro-Neo ${ }^{\text {stop }}$ construct generated as described in Results, Item 2, and then selected in liquid LIT medium supplemented with $200 \mu \mathrm{g} / \mathrm{mL}$ hygromycin B - cells were transferred to fresh hygromycin B-added LIT weekly, for 4-5 weeks. Then, exponentially-grown transfected cells were plated onto blood-agar medium [48.4\% LIT, 48.4\% brain-heart infusion and $2.5 \%$ defibrinated blood (Gomes et al., 1991)] supplemented with $200 \mu \mathrm{g} / \mathrm{mL}$ hygromycin B 
for selection of transfected clones. Colony forming units (CFU) were then picked and cultured in hygromycin-added liquid LIT medium, and after 7 days were subjected to genomic DNA extraction as follows: $10^{8}$ from each T. cruzi culture was centrifuged at $5000 \mathrm{x} g$ for $5 \mathrm{~min}$ and pelleted cells were resuspended in $100 \mu \mathrm{L}$ Milli-Q water and incubated at $95^{\circ} \mathrm{C}$ for $10 \mathrm{~min}$. After another centrifugation, the supernatants were collected and genotyping was conducted by PCR using primers 5 and 8 , listed in Table 1 .

\section{Determination of $T$. cruzi growth rate and survival}

A defined number $\left(5 \times 10^{6} / \mathrm{mL}\right)$ of transfected T. cruzi cells $\left(T\right.$. cruzi $\left.i^{\text {Neostop }}\right)$ were cultured for 2 days in fresh hygromycin B-added LIT, until they reached logarithmic growth phase, with cellular concentration around $2 \times 10^{7} / \mathrm{mL}$. After repeating this procedure three times, $T$. cruzi $^{\text {Neostop }}$ cells had their growth rate monitored for 7 or 42 days. After that, transfected cells were transferred to hygromycin B-added LIT supplemented with either 200 or 400 $\mu \mathrm{g} / \mathrm{mL}$ G418 and cultured for 2 days. The number of viable cells was determined using a hemocytometry chamber by the use of erythrosine as a vital stain for differentiation between live and dead cells. All experiments were performed in biological triplicates and results are reported in mean \pm standard deviation. Statistical analyses (one-way ANOVA) were performed using GraphPad Prism v6.0 (GraphPad Software, Inc.).

\section{T. cruzi genomic DNA extraction}

T. cruzi genomic DNA was extracted through cellular lysis, deproteination and precipitation, as described in Andrade et al. (1999). Briefly, a defined number of exponentially-grown $T$. cruzi cells $\left(10^{8}\right)$ were washed three times with PBS and incubated in $200 \mu \mathrm{L}$ of lysis solution $[(0.5 \%$ SDS, $100 \mu \mathrm{M}$ EDTA, and $10 \mathrm{mM}$ Tris- $\mathrm{HCl}(\mathrm{pH}$ 8.0)] with $20 \mu \mathrm{g} / \mathrm{mL}$ RNase, for $1 \mathrm{~h}$, at $37^{\circ} \mathrm{C}$. Then, 100 $\mu \mathrm{g} / \mathrm{mL}$ proteinase $\mathrm{K}$ was added to the lysate, which was incubated at $50{ }^{\circ} \mathrm{C}$ for $3 \mathrm{~h}$. Deproteination was conducted by the addition of $200 \mu \mathrm{L}$ saturated phenol followed by gentle homogenization and centrifugation; the organic phase was then dispose - the same procedures were repeated for the addition of $200 \mu \mathrm{L}$ of phenol/chloroform 1:1 (v/v) and 200 $\mu \mathrm{L}$ of chloroform. DNA precipitation was carried out using absolute isopropanol at $-80{ }^{\circ} \mathrm{C}$ overnight. The isopropanolic suspension of DNA was then centrifuged at 16,000 $\mathrm{x} g$, for $10 \mathrm{~min}$, and pelleted DNA was washed twice with ethanol $70 \%$ before being dried and resuspended in sterile MilliQ water.

\section{T. cruzi genomic DNA sequencing}

Genomic DNA from T. cruzi was sequenced through the Sanger method using a MegaBACE 1000 DNA Sequencing System (GE Healthcare). For each reaction, DYEnamic ET Dye Terminator MegaBACE kit and the specific set of primers were used. Sequences were analyzed by the Phred-Phrap algorithm (Ewing et al., 1998) and examined with MultAlin for multiple sequence alignment (Corpet, 1988).

\section{Mutation frequency assay}

A defined number of $T$. $c r u z i^{\text {Neostop }}$ epimastigotes $\left(10^{7}\right)$ was cultured for 42 days in hygromycin-added LIT in the presence or absence of $50 \mu \mathrm{M} \mathrm{H}_{2} \mathrm{O}_{2}$. Cells were then washed and resuspended in PBS, and counted as described in Materials and Methods, item 4. A volume of suspension containing $10^{8}$ cells were plated onto hygromycin B-added solid blood-agar, either in the presence or absence of G418. After 8 weeks, CFUs were counted, and mutation frequency was determined by dividing the number of CFUs observed on the plate per the number of cells $/ \mathrm{mL}$ present in the liquid LIT culture from which epimastigotes were collected.

\section{Results}

\section{Development of the $\mathrm{Neo}^{\text {stop }}$ reporter}

We developed a methodology to assess DNA mutation rates in $T$. cruzi based on a system that carries a Neo gene variant unable to encode an amino 3'-glycosyl phosphotransferase $\left[\mathrm{APH}\left(3^{\prime}\right)-\mathrm{II}\right]$ that displays its biological activity, unless a genomic mutational event takes place and restores this ability. APH(3')-II is an enzyme responsible for microbial resistance against aminoglycosides such as neomycin, kanamycin, and G418 (Hächler et al., 1996).

First, we sought to determine which segments from APH(3')-II were essential to its activity. For such, we generated three Neo gene shorter variants lacking their first 90, 180 and 270 nucleotides, using primers $2-4$, indicated in Table 1. Each Neo gene variant were ligated into pMAL c-2G (which harbors the lac promoter; Walker et al., 2010), giving rise to $\mathrm{Neo}^{\Delta 90}$-pMAL, $\mathrm{Neo}^{\Delta 180}$-pMAL and $\mathrm{Neo}^{\Delta 270}$ pMAL constructs (Figure 1A). We next transformed E. coli DH5 $\alpha$ with all aforementioned constructs, as well as with the wild type Neo construct (Neo ${ }^{\mathrm{WT}}$-pMAL) (Figure 1A), and bacterial transformants were selected from $2 \mathrm{xYT}$ plates supplemented with $100 \mu \mathrm{g} / \mathrm{mL}$ ampicillin. DH5 $\alpha$ transformants were cultivated overnight in liquid ampicillinadded 2 XYT, and then plated onto ampicillin-added solid 2xYT supplemented with $0.1 \mathrm{mM} \mathrm{IPTG}$, in the presence or absence of $10 \mu \mathrm{g} / \mathrm{mL}$ kanamycin. We then verified that, unlike $\mathrm{Neo}^{\text {WT }}$, none of the three obtained Neo gene variants $\left(\mathrm{NeO}^{\Delta 90}, \mathrm{Neo}^{\Delta 180}\right.$, and $\mathrm{NeO}^{\Delta 270}$ ) were able to confer DH5 $\alpha$ resistance against kanamycin (Figure 1A, B). We therefore concluded that the first 30 amino acids of the $\mathrm{N}$-terminal portion of APH(3')-II are essential to its biological activity.

Once we determined that the Neo gene is required to promote resistance against aminoglycosides, we decided to introduce a premature stop codon right after the $\mathrm{Neo}^{\text {WT }}$ 
A

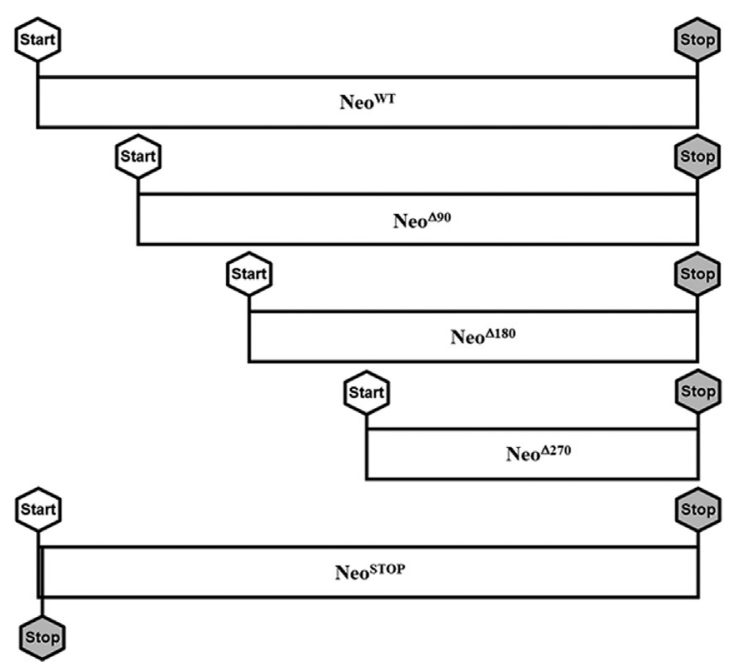

B

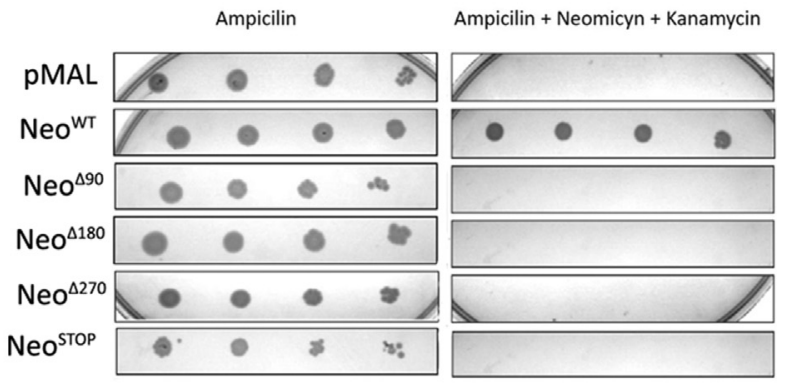

Figure 1 - The N-terminal region of Neo is required to promote resistance against kanamycin. Wild-type Neo gene $\left(\mathrm{Neo}^{\mathrm{WT}}\right)$ and its variants $\left(\mathrm{Neo}^{\Delta 90}\right.$, $\mathrm{Neo}^{\Delta 180}, \mathrm{Neo}^{\Delta 270}$ and $\mathrm{Neo}^{\mathrm{STOP}}$ ) were obtained as described in Materials and Methods, item 1, and kanamycin- and neomycin-resistance assay was conducted as described in Materials and Methods, item 2. (A) Diagram depicting wild-type Neo gene and deletions of N-terminal segments, which give rise to Neo gene variants. (B) $\mathrm{Neo}^{\Delta 90}, \mathrm{Neo}^{\Delta 180}, \mathrm{Neo}^{\Delta 270}$ and $\mathrm{Neo}^{\mathrm{STOP}}$ were unable to confer to DH5 $\alpha$ resistance against kanamycin. pMAL: empty vector.

gene start codon using primers 5 and 7 listed in Table 1, creating the $\mathrm{Neo}^{\text {stop }}$ variant, in which a $\mathrm{G}$ - its fourth base - is substituted by a T, generating the stop codon TGA (Figure $2 \mathrm{~A})$. This premature stop codon prevents the formation of APH(3')-II, completely abrogating the growth capacity of DH5 $\alpha$ in the presence of kanamycin (Figure 1B). We next manually performed an in silico prediction of possible mutations that would restore the translation of the $\mathrm{N}$-terminal portion of $\mathrm{APH}\left(3^{\prime}\right)-\mathrm{II}$, and thus provide resistance against aminoglycosides. Interestingly, from all predicted mutational events (Figure 2B), two of them $-\mathrm{G} \rightarrow \mathrm{T}$ at position 5 , and $\mathrm{T} \rightarrow \mathrm{G}$ at position 15 - are classic mutations generated by cellular exposure to $\mathrm{H}_{2} \mathrm{O}_{2}$ (Shibutani et al., 1991).

\section{Long-term cultivation induces mutational events in T. cruzi}

After (i) observing that DH5 $\alpha$ transformed with the $\mathrm{Neo}^{\text {stop }}$-pMAL construct did not exhibit growth in $2 \mathrm{xYT}$ supplemented with kanamycin (Figure 1B), and (ii) that oxidation could lead to mutational events that might restore the translation of $\mathrm{APH}\left(3^{\prime}\right)$-II from the $\mathrm{Neo}^{\text {stop }}$ variant (Figure 2B), we sought to transfect $T$. cruzi with the $\mathrm{Neo}^{\text {stop }}$ gene variant. As expected, we were unable to observe, through erythrosine vital stain assay, visible growth of clones \#1 and \#5 of T. cruzi ${ }^{\text {Neostop }}$ cultured in hygromycinadded liquid LIT supplemented with G418 (Figure 3A). We then investigate if long-term cultivation - i.e., 42 days - of T. cruzi $^{\text {Neostop }}$ was capable of generating G418-insensitive clones for such, clones $\# 1$ and $\# 5$ were subject to the same experimental design described above, being cultured for 42 days, instead. Surprisingly, upon the increase of the cultivation period, we were able to verify the presence of G418resistant $T$. cruzi cells from $\mathrm{Neo}^{\text {Stop }}$ clones $\# 1$ and $\# 5$ in hygromycin-added liquid LIT supplemented with 200 or 400 mM G418 (Figure 3B).

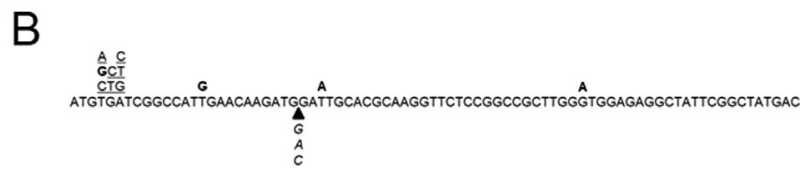

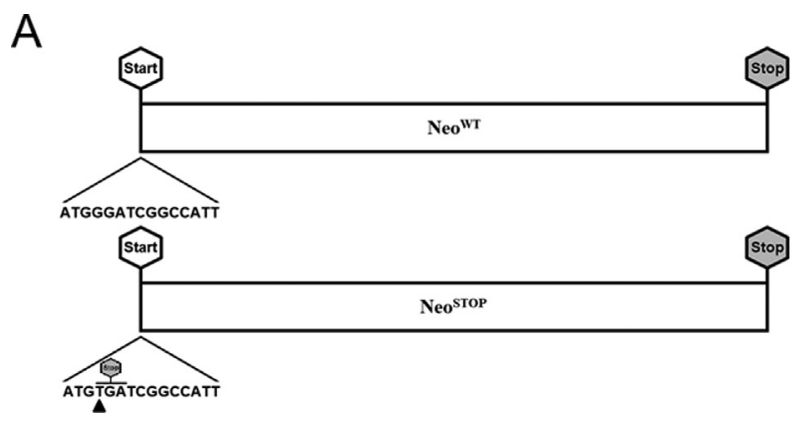

Figure 2 - Construction of the $\mathrm{Neo}^{\text {stop }}$ reporter and manually predicted mutations within its first seventy nucleotides. (A) The Neo ${ }^{\text {stop }}$ reporter was constructed substituting a guanine for a thymine at position 4 (as indicated by the arrow), generating the stop codon TGA right after the start codon ATG, as described in Materials and Methods, item 1. (B) Manually predicted spontaneous and oxidation-induced mutations within the first seventy nucleotides of the $\mathrm{Ne}^{\text {stop }}$ reporter are indicated by underlined and bold-type letters, respectively. Insertion of a guanine, cytosine, and adenine at position 26 (indicated by italicized letters) can convert the ATG sequence found at positions 23-25 into an in-frame start codon. 
A

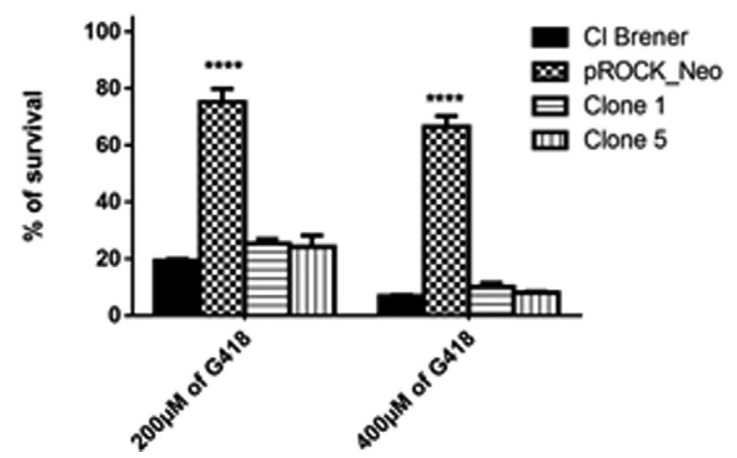

B

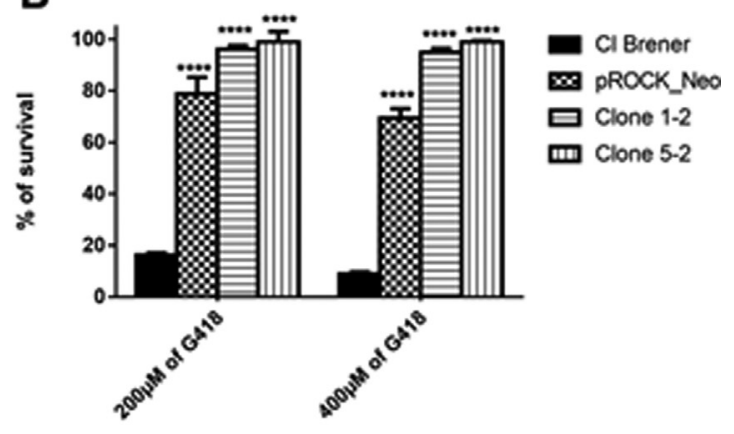

Figure 3 - Long term incubation leads to selection of T. cruzi ${ }^{\text {Neostop }}$ revertant clones. T. cruzi $^{\text {neostop }}$ transfection, selection, genotyping, and growth rate and survival were determined as described in Materials and Methods, items 3 and 4. Panel A: Resistance of T. cruzi ${ }^{\text {Neostop }}$ epimastigotes against G418 after 7 days of cellular growth in liquid medium. (B) Resistance of T. cruzi ${ }^{\text {Neostop }}$ epimastigotes against G418 after 42 days of growth in liquid medium, indicating that cell duplication allows mutational events in T. cruzi. Epimastigotes harboring pROCK Neo construct were used as positive controls for aminoglycoside resistance. Statistical analyses (One-Way ANOVA) were conducted using GraphPad Prism software v6.0. $* * * * p<0.001$ vs. WT.

\section{Oxidative stress increases mutational events in $T$. cruzi}

Given the fact that long-term cultivation allows the observation of mutational events in $T$. cruzi, we decided to take advantage of the established protocol for isolation of $T$. cruzi clones using solid blood-agar to determine the number of CFUs of G418-insensitive T. cruzi $i^{\text {Neostop }}$ generated from a defined number of plated cells - this would allow us to determine the frequency of mutation of $T$. cruzi. Then, $1 \times 10^{8}$ cells from $\mathrm{Neo}^{\text {Stop }}$ clones $\# 1$ and $\# 5$, previously cultured in hygromycin $\mathrm{B}$-added liquid LIT for 42 days, in the presence or absence of $50 \mu \mathrm{M} \mathrm{H}_{2} \mathrm{O}_{2}$, were plated onto hygromycin B-added solid blood-agar, and the number of CFUs were determined, as described in Material and Methods, item 7. We verified that T. cruzi ${ }^{\text {Neostop }}$ cultured in the presence of $\mathrm{H}_{2} \mathrm{O}_{2}$, showed a mutation frequency of $1.56 \times 10^{-7}$, while parasites cultured in control conditions, i.e., in the absence of $\mathrm{H}_{2} \mathrm{O}_{2}$, exhibited a mutation frequency of $0.71 \times 10^{-7}$. This observation indicated that there is a two-fold increase in mutation frequency when $T$. cruzi faces situations of environmental oxidative stress. Besides, the experimental design was sensitive enough to allow us to identify the basal frequency of genomic mutations of $T$. $\mathrm{cruzi}^{\text {Neostop }}$, i.e., the frequency of mutational events observed in parasites that were not exposed to $\mathrm{H}_{2} \mathrm{O}_{2}$ during this assay. This basal frequency - lower than the one observed in the presence of $\mathrm{H}_{2} \mathrm{O}_{2}$ - may indicate the rate of oxidation-independent mutational events that probably take place spontaneously in $T$. cruzi.

\section{Screening genetic mutations from G418-resistant $T$. cruzi $^{\text {Neostop }}$}

To determine the identity of the mutations present in G418-resistant $T$. cruzi ${ }^{\text {Neostop }}$ clones generated after 42 days of culture in the presence or absence of $\mathrm{H}_{2} \mathrm{O}_{2}$ (Material and Methods, item 7), we next selected seven of them (\#1-2 and $\# 5-2$, from cultures conducted in the absence of $\mathrm{H}_{2} \mathrm{O}_{2}$;
$\# 18-2, \# 34-2, \# 36-2, \# 40-2$ and \#43-2, from cultures carried out in the presence of $\mathrm{H}_{2} \mathrm{O}_{2}$ ) aiming to isolate, extract, and sequence their genomic DNA by the Sanger method. Through this screening we verified that (i) $T$. cruzi ${ }^{\text {Neostop }}$ clones \#1-2, \#5-2, \#36-2, and \#43-2 presented mutations that abrogate the TGA stop codon previously inserted in $\mathrm{Neo}^{\text {stop }}$ [\#1-2: G $\rightarrow$ A transversion, probably promoted by replicative stress; \#5-2: $\mathrm{G} \rightarrow \mathrm{C}$ transversion; \#36-2 and \#43-2: $\mathrm{G} \rightarrow \mathrm{T}$ transversions, generated by a 8 -oxoguanine (8-oxoG) formed by the oxidation of a guanine from the genomic DNA]; and that (ii) clones \#18-2, \#34-2 and \#40-2 showed a $T \rightarrow G$ transversion - probably caused by 8-oxoG formation by the oxidation of a guanine from the nucleotide pool at positon 15, allowing the creation of an in-frame start codon at position 13 (Figure 4A). It is noteworthy that all G418-resistant T. cruzi ${ }^{\text {Neostop }}$ clones picked from the 42-day cellular culture under oxidative stress conditions (\#18-2, \#34-2, \#36-2, \#40-2 and \#43-2) presented classic transversions that arise from the exposure to reactive oxygen species (Figure 4A). Also, clones \#1-2 and \#5-2, selected from non-oxidative cellular cultures, despite presenting mutations that abrogate the inserted stop-codon, lacked the classic mutation signature promoted by conditions of oxidative stress.

\section{The $\mathrm{NeO}^{\text {stopt }} \rightarrow \mathrm{G}$ reporter confers kanamycin resistance to $\mathrm{DH} 5 \alpha$}

We next designed a forward primer carrying a guanine in its $4^{\text {th }}$ position (\#6, Table 1 ) to artificially obtain the $\mathrm{Neo}^{\text {stop }}$ gene variant mimicking the oxidation-induced $\mathrm{T} \rightarrow \mathrm{G}$ mutation, which creates a downstream start codon, as found in $\mathrm{Neo}^{\text {stop }}$ clones \#18-2, \#34-2 and \#40-2 (Figure $4 \mathrm{~A})$. The resultant amplicon $\left(\mathrm{Neo}^{\text {stopT }} \rightarrow \mathrm{G}\right.$ ) was ligated into pMAL c-2G plasmid, generating the Neo ${ }^{\text {stopT }} \rightarrow$ G-pMAL construct, which was used to transform $\mathrm{DH} 5 \alpha$, whose transformants were selected from ampicillin-supplemented 
A

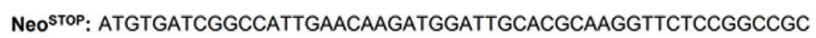
Clone \#1-2: ATGTCATCGGCCATTGAACAAGATGGATTGCACGCAAGGTTCTCCGGCCGC Clone \#5-2: ATGAGATCGGCCATTGAACAAGATGGATTGCACGCAAGGTTCTCCGGCCGC Clone \#36-2: ATGTTATCGGCCATTGAACAAGATGGATTGCACGCAAGGTTCTCCGGCCGC Clone \#43-2: ATGTTATCGGCCATTGAACAAGATGGATTGCACGCAAGGTTCTCCGGCCGC Clone \#18-2: ATGTTATCGGCCATGGAACAAGATGGATTGCACGCAAGGTTCTCCGGCCGC Clone \#34-2: ATGTGATCGGCCATGGAACAAGATGGATTGCACGCAAGGTTCTCCGGCCGC Clone \#40-2: ATGTGATCGGCCATGGAACAAGATGGATTGCACGCAAGGTTCTCCGGCCGC
B

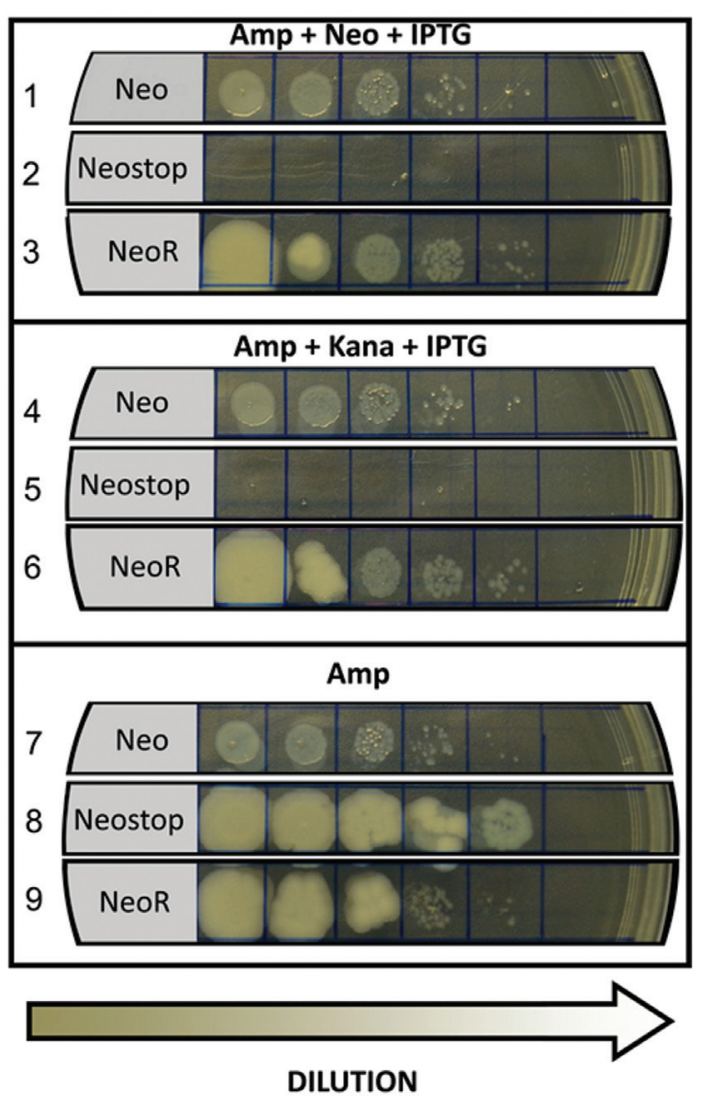

Figure 4 - $\mathrm{Neo}^{\text {stop T }} \rightarrow \mathrm{G}$ transversion can rescue aminoglycoside resistance to DH5 $\alpha$. (A) Sequencing analysis of G418-resistant clones shows that exposure to $\mathrm{H}_{2} \mathrm{O}_{2}$ leads to classic transversions arisen from oxidative damage (bold-type letters). Oxidative-unrelated mutations were also found (underlined letters). (B) To verify if $\mathrm{T} \rightarrow \mathrm{G}$ at position 15 could restore aminoglycoside resistance in DH5 $\alpha$ we generated this transversion through the use of the primer Neo ${ }^{\text {stop }} \rightarrow$ G_FW (\#6, Table 1) - which generates a start codon into the $\mathrm{Neo}^{\text {stop }}$ - to obtain the Neo ${ }^{\text {stopT }} \rightarrow$ G reporter, that confers kanamycin- and neomycin-resistance to $\mathrm{DH} 5 \alpha$.

$2 \mathrm{xYT}$ plates. After isolation, the $\mathrm{Ne}^{\mathrm{stop} T} \rightarrow \mathrm{G}-\mathrm{pMAL}$ construct was used to obtain DH5 $\alpha$ transformants from solid ampicillin-added 2xYT plates. Once selected, one clone from these bacterial transformants was cultured overnight in liquid ampicillin-added 2xYT, and then plated onto ampicillin-added solid 2xYT supplemented with $0.1 \mathrm{mM}$ IPTG, in the presence or absence of $10 \mu \mathrm{g} / \mathrm{mL}$ kanamycin. We were then able to verify that DH5 $\alpha$ harboring $\mathrm{Neo}^{\text {stopT }} \rightarrow \mathrm{G}$ became G418-resistant (Figure 4B), confirming that the aminoglycoside resistance observed in the $T$. cruzi $^{\text {Neostop }}$ clones \#18-2, \#34-2 and \#40-2 is in fact promoted by the $\mathrm{T} \rightarrow \mathrm{G}$ mutation, a nucleotide transversion classically induced by oxidants (Shibutani et al., 1991).

\section{Discussion}

Genetic diversity is an important factor that is directly related to adaptation and survival of T. cruzi in its hosts; in fact, DNA metabolism and mutagenesis may allow this parasite to increase the chances to adapt to different environments during its complex life cycle (Machado-Silva et al., 2016). In this sense, the study of mechanisms that govern this phenomenon is crucial for the understanding of how $T$. cruzi evade the immune system and show resistance against drugs, and for the development of new therapeutic strategies. However, currently, other than a restricted number of studies employing in silico approaches to study mutagenesis and variability in T. cruzi (Azuaje et al., 2007a,b), there is scarce information regarding the exact cellular events that may generate intra-specific genomic variability and few biological assays that allow the determination and detection of mutation rates in this parasite.

The Neo gene encodes APH(3')-II, a phosphotransferase that contains 267 amino acids, and is responsible for conferring microbial resistance against aminoglycosides (Hächler et al., 1996). APH(3')-II displays an ATP biding-site and can transfer the $\gamma$-phosphoryl group from an ATP molecule to the aminoglycoside, converting the latter to its phosphorylated, inactive form (Eustice and Wilhelm, 1984; Shaw et al., 1993; Thompson et al., 2002). We generated a number of mutations in the Neo gene, which gave rise to shorter $\mathrm{APH}\left(3^{\prime}\right)$-II variant forms (Table, 1, Figure 1A) that were ineffective in conferring DH5 $\alpha$ resistance against kanamycin (Figure 1B). Then, once we determined 
that the $\mathrm{N}$-terminal segment of $\mathrm{Neo}$ was required to provide resistance against kanamycin and G418, we introduced a premature stop-codon right after Neo's ATG through a $\mathrm{G} \rightarrow \mathrm{T}$ mutation at position 4 (Figure 2A), creating a variant $\left(\mathrm{Neo}^{\text {stop }}\right)$ that would re-establish resistance against aminoglycosides if the mutated codon underwent a mutational event. This was observed when T. cruzi ${ }^{\text {Neostop }}$ was cultivated for 42 days in hygromycin B-added liquid LIT (Figure 3).

During its life cycle, $T$. cruzi undergoes an obligatory intracellular amastigote stage in which the immune system promotes the release of reactive oxygen and nitrogen species to halt the infection (Piacenza et al., 2009); thus, replication of amastigotes under a scenario of oxidative stress can promote a condition from which mutated cells can ultimately increase the pool of mutated $T$. cruzi, which could lead to intra-specific genetic diversity. Although epimastigotes and amastigotes are subjected to different extents of oxidative stress, data from the literature (Aguiar et al., 2013), as well as unpublished observations from our group, suggest that both aforementioned $T$. cruzi life forms are equally affected by oxidative stress and share the same responses against this biological condition. Therefore, the observation that epimastigotes treated with $\mathrm{H}_{2} \mathrm{O}_{2}$ display a 2 -fold increase in mutational events (Results, item 3 ) suggests that oxidative stress promoted by the host may play a direct role in genetic variability of $T$. cruzi amastigotes. In fact, for several other organisms, including E. coli, Helicobacter pylori, Salmonella typhimurium, Bacillus subtilis, Pseudomonas, Clostridium, Saccharomyces cerevisiae, and Candida albicans, increased mutation rates are often correlated with increased survival and infection rates in adverse conditions (Wang et al., 2001; Foster, 2000; Linz et al., 2014). In this manner, the increase in the number of G418-resistant T. cruzi $^{\text {Neostop }}$ clones after longterm oxidative insult (Figure 3) suggests that this type of stress could stimulate intra-specific genetic variability.

It is well-established that oxidative stress promotes a range of modifications in nucleic acids, such as doublestrand breaks and nitrogenous base modification (Friedberg et al., 2006). Interestingly, the generation of 8-oxoG, one of the most frequent lesions derived from oxidative stress, has a high mutagenic potential, since the oxidized guanine, if localized in the genomic DNA, promotes a mismatched pairing with adenine resulting in $\mathrm{G} \rightarrow \mathrm{T}$ or $\mathrm{C} \rightarrow \mathrm{A}$ transversions. In addition, the generation of 8-oxoG in the nucleotide pool also promotes a $\mathrm{T} \rightarrow \mathrm{G}$ transversion, consequently leading to nucleotide mismatches (Dizdaroglu et al., 2002; van Loon et al., 2010). In fact, the severity of effects that can arise from the formation of 8-oxoG became evident when the GO system - a pathway specialized in preventing mutagenicity promoted by 8-oxoG, comprised of three enzymes, namely MYH (MutY homologue), MTH (MutT homologue), and OGG1 (FPG homologue) - was first described (Michaels et al., 1992; Michaels and Miller, 1992; David et al., 2007).

In $T$. cruzi, long-term exposure to $\mathrm{H}_{2} \mathrm{O}_{2}$ induced DNA mutations related to the generation of 8 -oxoG, as clones $\# 18-2$, \#34-2 and \#40-2 showed mutations that are likely consequence of a guanine oxidation (Figure 4A). Likewise, clones \#36-2 and \#43-2 also presented formation of 8-oxoG mutations, since guanine in DNA undergoes a mispairment with adenine during replication (Figure 4A). The mispairing observed in clones \#1-2 and \#5-2 - which were not exposed to $\mathrm{H}_{2} \mathrm{O}_{2}$ - are possibly products of an impaired replication process induced by a wobble conformation, although the DNA template and protein conformation are not disturbed (Johnson and Beese, 2004). These mismatches allow the formation of a structure closer to Watson-Crick base pair than that one observed in G:A and A:G mismatches. Altogether, these verifications indicate that mutations observed in $T$. cruzi cells exposed to $\mathrm{H}_{2} \mathrm{O}_{2}$ are products of generation or misincorporation of 8-oxoG in the DNA, since those mutations are deleterious and do not easily arise in normal environments, considering the abnormalities they cause to the polymerase structure (Johnson and Beese, 2004). Alterations in DNA metabolism can also increase genetic mutation frequency (Castillo-Acosta et al., 2012). Organisms like yeast seem to preferentially insert cytosine opposing apurinic/apyrimidinic sites, and this mechanism could lead to the increase of AT $\rightarrow$ GC transversions (Thomas et al., 1997).

As suggested for T. cruzi, the presence of mutations, to some extent, are possibly related to the survival of some other organisms. In fact, Trypanosoma brucei strain relies on variant surface glycoproteins (VSG) switching to escape from the host immune system, a process in which recombination plays a crucial role (Hartley and McCulloch, 2008; Horn and McCulloch, 2010). Deletion of deoxyuridin 5'triphosphate pyrophosphatase (dUTPase) can cause a 9fold increase in spontaneous mutation, and the appearance of double strand breaks in $T$. brucei, which could lead to a recombination process, increasing VSG switching (Castillo-Acosta et al., 2012).

In this work, through a novel assay to assess mutational events in $T$. cruzi, we demonstrated that oxidative stress increases the mutation frequency in this parasite. We hypothesize that the 2-fold increase in mutation frequency after exposure to $\mathrm{H}_{2} \mathrm{O}_{2}$ - which mimics the reactive oxygen species released by human macrophages - indicates that this mutational mechanism, combined with the GO repair system - could generate $T$. cruzi 's intra-specific genetic diversity that can be important to help this trypanosomatid to evade the immune system and be resistant to drug therapy, ultimately allowing this parasite to survive in stressful environments. 


\section{Acknowledgments}

We thank Neuza Antunes Rodrigues for excellent technical support. This work was supported by the following Brazilian research funding institutions: $\mathrm{CNPq}$ (Conselho Nacional para o Desenvolvimento Científico e Tecnológico) and FAPEMIG (Fundação de Amparo a Pesquisa de Minas Gerais).

\section{References}

Aguiar PH, Furtado C, Repolês BM, Ribeiro GA, Mendes IC, Peloso EF, Gadelha FR, Macedo AM, Franco GR, Pena SD et al. (2013) Oxidative stress and DNA lesions: the role of 8-oxoguanine lesions in Trypanosoma cruzi cell viability. PLoS Negl Trop Dis 7:e2279.

Andrade LO, Machado CR, Chiari E, Pena SD and Macedo AM (1999) Differential Tissue Distribution of Diverse Clones of Trypanosoma Cruzi in Infected Mice. Mol Biochem Parasitol 100:163-72.

Andrade LO, Galvão LM, Meirelles MdeN, Chiari E, Pena SD and Macedo AM (2010) Differential tissue tropism of Trypanosoma cruzi strains: an in vitro study. Mem Inst Oswaldo Cruz 105:834-837.

Augusto-Pinto L, Teixeira SM, Pena SD and Machado CR (2003) Single-nucleotide polymorphisms of the Trypanosoma cruzi MSH2 gene support the existence of three phylogenetic lineages presenting differences in mismatch-repair efficiency. Genetics 164:117-126.

Azuaje F, Ramirez JL and Da Silveira JF (2007a) An exploration of the genetic robustness landscape of surface protein families in the human protozoan parasite Trypanosoma cruzi. IEEE Trans Nanobiosci 6:223-228.

Azuaje FJ, Ramirez JL and da Silveira, JF (2007b) In silico, biologically-inspired modelling of genomic variation generation in surface proteins of Trypanosoma cruzi. Kinetoplastid Biol Dis 6:6.

Baptista RP, D’Ávila DA, Segatto M, do Valle ÍF, Franco GR, Valadares HM, Gontijo ED, Galvão LM, Pena SD, Chiari E et al. (2014) Evidence of substantial recombination among Trypanosoma cruzi II strains from Minas Gerais. Infect Genet Evol 22:183-191.

Bensasson D (2011) Evidence for a high mutation rate at rapidly evolving yeast centromeres. BMC Evol Biol 11:211.

Bergkessel M and Guthrie C (2013) Colony PCR. Methods Enzymol 529:299-309.

Burgos JM, Risso MG, Brenière SF, Barnabé C, Campetella O and Leguizamón MS (2013) Differential distribution of genes encoding the virulence factor trans-sialidase along Trypanosoma cruzi discrete typing units. PLoS One 8:e58967.

Castillo-Acosta VM, Aguilar-Pereyra F, Bart JM, Navarro M, Ruiz-Pérez LM, Vidal AE and González-Pacanowska D (2012) Increased uracil insertion in DNA is cytotoxic and increases the frequency of mutation, double strand break formation and VSG switching in Trypanosoma brucei. DNA Repair 11:986-995.

Choi SS, Chivers PT and Berg DE (2011) Point mutations in Helicobacter pylori's fur regulatory gene that alter resistance to metronidazole, a prodrug activated by chemical reduction. PloS One 6:e18236.
Corpet F (1988) Multiple sequence alignment with hierarchical clustering. Nucleic Acids Res 16:10881-10890.

da Rocha WD, Silva RA, Bartholomeu DC, Pires SF, Freitas JM, Macedo AM, Vazquez MP, Levin MJ and Teixeira SM (2004) Expression of exogenous genes in Trypanosoma cruzi: improving vectors and electroporation protocols. Parasitol Res 92:113-120.

David SS, Shea VLO and Kundu S (2007) Base excision repair of oxidative DNA damage. Nature 447:941-950.

de Noya BA and González ON (2015) An ecological overview on the factors that drives to Trypanosoma cruzi oral transmission. Acta Trop 151:94-102.

Dizdaroglu M, Jaruga P, Birincioglu M and Rodriguez H (2002) Free radical-induced damage to DNA: Mechanisms and measurement. Free Radic Biol Med 32:1102-1115.

Eustice DC and Wilhelm JM (1984) Mechanisms of action of aminoglycoside antibiotics in eucaryotic protein synthesis. Antimicrob Agents Chemother 26:53-60.

Ewing B, Hillier L, Wendl MC and Green P (1998) Base-calling of automated sequencer traces using phred. I. Accuracy assessment. Genome Res 8:175-185.

Ford CB, Shah RR, Maeda MK, Gagneux S, Murray MB, Cohen T, Johnston JC, Gardy J, Lipsitch M and Fortune SM (2013) Mycobacterium tuberculosis mutation rate estimates from different lineages predict substantial differences in the emergence of drug-resistant tuberculosis. Nat Genet 45:784-790.

Frasch AC (2000) Functional diversity in the trans-sialidase and mucin families in Trypanosoma cruzi. Parasitol Today 16:282-286.

Friedberg EC, Walker GC, Siede W, Wood RD, Schultz RA and Ellenburger T (2006) DNA repair and mutagenesis. 2nd edition. ASM Pres, Washington, 1118 p.

Foster PL (2000) Adaptive mutation: implications for evolution. Bioessays 22:1067-1074.

Glassner BJ, Rasmussen LJ, Najarian MT, Posnick LM and Samson LD (1998) Generation of a strong mutator phenotype in yeast by imbalanced base excision repair. Proc Natl Acad Sci U S A 95:9997-10002.

Gomes ML, Araujo SM and Chiari E (1991) Trypanosoma cruzi: Growth of clones on solid medium using culture and blood forms. Mem Inst Oswaldo Cruz 86:131-132.

Gonzales MF, Brooks T, Pukatzki SU and Provenzano D (2013) Rapid protocol for preparation of electrocompetent Escherichia coli and Vibrio cholerae. J Vis Exp 8:80.

Hächler H, Santanam P and Kayser FH (1996) Sequence and characterization of a novel chromosomal aminoglycoside phosphotransferase gene, aph (3')-IIb, in Pseudomonas aeruginosa. Antimicrob Agents Chemother 40:1254-1256.

Hartley CL and McCulloch R (2008) Trypanosoma brucei BRCA2 acts in antigenic variation and has undergone a recent expansion in BRC repeat number that is important during homologous recombination. Mol Microbiol 68:1237-1251.

Hoeijmakers JHJ (2001) Genome maintenance mechanisms for preventing cancer. Nature 411:366-374.

Horn D and McCulloch R (2010) Molecular mechanisms underlying the control of antigenic variation in African trypanosomes. Curr Opin Microbiol 13:700-705.

Johnson SJ and Beese LS (2004) Structures of mismatch replication errors observed in a DNA polymerase. Cell 116:803816. 
Linz B, Windsor HM, McGraw JJ, Hansen LM, Gajewski JP, Tomsho LP, Hake CM, Solnick JV, Schuster SC and Marshall BJ (2014) A mutation burst during the acute phase of Helicobacter pylori infection in humans and rhesus macaques. Nat Commun 13:4165.

Macedo AM, Machado CR, Oliveira RP and Pena SD (2004) Trypanosoma cruzi: Genetic structure of populations and relevance of genetic variability to the pathogenesis of chagas disease. Mem Inst Oswaldo Cruz 99:1-12.

Machado-Silva A, Cerqueira PG, Grazielle-Silva V, Gadelha FR, Peloso EF, Teixeira SM and Machado CR (2016) How Trypanosoma cruzi deals with oxidative stress: Antioxidant defence and DNA repair pathways. Mutat Res Rev Mutat Res 767:8-22.

Magni GE and von Borstel RC (1962) Different rates of spontaneous mutation during mitosis and meiosis in yeast. Genetics 47:1097-1108

Matic I, Radman M, Taddei F, Picard B, Doit C, Bingen E, Denamur E, Elion J (1997) Highly Variable Mutation Rates in Commensal and Pathogenic Escherichia Coli. Science 277:1833-34.

Michaels ML and Miller JH (1992) The GO system protects organisms from the mutagenic effect of the spontaneous lesion 8-hydroxyguanine (7,8-dihydro-8-oxoguanine). J Bacteriol 174:6321-6325.

Michaels ML, Cruz C, Grollman AP and Miller JH (1992) Evidence that MutY and MutM combine to prevent mutations by an oxidatively damaged form of guanine in DNA. Proc Natl Acad Sci U S A 89:7022-7025.

Patrushev LI and Minkevich IG (2008) The problem of the eukaryotic genome size. Biochemistry 73:1519-1552.

Piacenza L, Alvarez MN, Peluffo G and Radi R (2009) Fighting the oxidative assault: The Trypanosoma cruzi journey to infection. Curr Opin Microbiol 12:415-421.

Prata A (2001) Clinical and epidemiological aspects of Chagas disease. Lancet Infect Dis 1:92-100.

Provan J, Soranzo N, Wilson NJ, Goldstein DB and Powell W (1999) A low mutation rate for chloroplast microsatellites. Genetics 153:943-947.

Rassi Jr A and Marin-Neto JÁ (2010) Chagas disease. Lancet 375:1388-1402.

Revollo S, Oury B, Laurent JP, Barnabé C, Quesney V, Carrière V, Noël S and Tibayrenc M. (1998) Trypanosoma cruzi: Impact of clonal evolution of the parasite on its biological and medical properties. Exp Parasitol 89:30-39.

Rosche WA and Foster PL (2000) Determining mutation rates in bacterial populations. Methods 20:4-17.

Schmunis GA (2007) Epidemiology of Chagas disease in non-endemic countries: the role of international migration. Mem Inst Oswaldo Cruz 102 Suppl 1:75-85.

Shaw KJ, Rather PN, Hare RS and Miller GH (1993) Molecular genetics of aminoglycoside resistance genes and familial relationships of the aminoglycoside-modifying enzymes. Microbiol Rev 57:138-163.
Shibutani S, Takeshita M and Grollman AP (1991) Insertion of specific bases during DNA synthesis past the oxidationdamaged base 8-oxodG. Nature 349:431-434.

Shikanai-Yasuda MA, Marcondes CB, Guedes LA, Siqueira GS, Barone AA, Dias JC, Amato Neto V, Tolezano JE, Peres BA, Arruda Jr ER et al. (1991) Possible oral transmission of acute Chagas' disease in Brazil. Rev Inst Med Trop Sao Paulo 33:351-357.

Shikazono N, Yokota Y, Kitamura S, Suzuki C, Watanabe H, Tano S and Tanaka A (2003) Mutation rate and novel tt mutants of Arabidopsis thaliana induced by carbon ions. Genetics 163:1449-1455.

Steinberg CM, Diuision B and Ridge O (1971) Inheritance of spontaneous mutability in yeast. Genetics 69:17-27.

Taddei F, Vulic M, Radman M and Matic I (1997) Genetic variability and adaptation to stress. EXS 83:271-290.

Thomas D, Scot AD, Barbey R, Padula M and Boiteux S (1997) Inactivation of OGG1 increases the incidence of G.C $\rightarrow$ T.A transversions in Saccharomyces cerevisiae: Evidence for endogenous oxidative damage to DNA in eukaryotic cells. Mol Gen Genet 254:171-178.

Thompson PR, Boehr DD, Berghuis AM and Wright GD (2002) Mechanism of aminoglycoside antibiotic kinase APH(3')IIIa: role of the nucleotide positioning loop. Biochemistry 41:7001-7007.

van Loon B, Markkanen E and Hübscher U (2010) Oxygen as a friend and enemy: How to combat the mutational potential of 8-oxo-guanine. DNA Repair 9:604-616.

Wang G, Wilson TJ, Jiang Q and Taylor DE (2001) Spontaneous mutations that confer antibiotic resistance in Helicobacter pylori. Antimicrob Agents Chemother 45:727-733.

Zingales B, Andrade SG, Briones MR, Campbell DA, Chiari E, Fernandes O, Guhl F, Lages-Silva E, Macedo AM, Machado CR et al. (2009) A new consensus for Trypanosoma cruzi intraspecific nomenclature: Second revision meeting recommends TcI to TcVI. Mem Inst Oswaldo Cruz 104:10511054.

Zingales B, Miles MA, Campbell DA, Tibayrenc M, Macedo AM, Teixeira MM, Schijman AG, Llewellyn MS, Lages-Silva E, Machado CR et al. (2012) The revised Trypanosoma cruzi subspecific nomenclature: rationale, epidemiological relevance and research applications. Infect Genet Evol 12:240253.

\section{Internet Resources}

WHO Chagas disease (American trypanosomiasis) fact sheet, http://www.who.int/mediacentre/factsheets/fs340/en/ (November 13, 2017).

Associate Editor: Carlos F.M. Menck

License information: This is an open-access article distributed under the terms of the Creative Commons Attribution License (type CC-BY), which permits unrestricted use, distribution and reproduction in any medium, provided the original article is properly cited. 